\title{
Rejuvenation and decompression events recorded in alkali feldspar from plutonic rocks
}

\author{
SuSANNE SEITZ*', GUILHERME A. R. GuALDA', ROBERT \\ A. WIEBE ${ }^{2}$ AND LUCA CARICCHI ${ }^{3}$ \\ Vanderbilt University, USA (*correspondance: \\ susanne.seitz@vanderbilt.edu, \\ g.gualda@vanderbilt.edu) \\ Unniversity of California Davis, USA \\ (rawiebe@ucdavis.edu) \\ University of Geneva, Switzerland \\ (luca.caricchi@unige.ch)
}

Zoned minerals preserve information about their growth conditions, by chnaging their chemistry as function of temperature, pressure and melt composition. By carefully looking at a mineral population we can determine characteristics of the main stages of the evolution of magmatic systems.

We study alkali feldspar from two magmatic systems: the Tuolumne Intrusive Complex (TIC) in California; and the Cadillac Mountain Intrusive Complex (CMIC) in Maine, with the aim of deciphering chemical signatures of rejuvenation and decompression. We characterize the chemical zoning of alkali feldspar using X-ray tomography, BSE, EDS-SEM and LA-ICPMS profiles. We use hierarchical clustering based on major and trace elements to objectively identify compositional groups for each chemical profile. By reducing the complexity of chemical zoning to one dimention (i.e. cluster number) we can easily trace the evolution of the conditions of growth and identify rejuvenation and decompression events.

Alkali feldspar crystals $(\leq 20 \mathrm{~cm})$ from the Cathedral Peak unit of the TIC occur predominantly disperse and only make between $8-12 \%$ of the total crystal population. They are mostly homogeneous in major element, and markedly oscillatory zoned in trace elements such as $\mathrm{Ba}, \mathrm{Sr}$, and $\mathrm{Rb}$. Overall the crystals show a decreasing trend of Ba towards the rim. In some crystals this sequence is repeated twice. This suggests melt recharge in a melt-rich magmatic system.

Alkali feldspar from the Somesville granite and the Shatter Zone unit of the CMIC show unzoned cores and oscillatory zoned rims in major and trace elements, likely recording multiple decompression events. Diffusion time scales based on major and trace elements suggest alkali feldspar growth and cooling of the magmatic system within max. 30000 years. Several decompression events occured no longer than 300 years before the system cooled. 